\title{
Destino Manifiesto y el Sur más allá del Mississippi: las leyes naturales y la extensión de la esclavitud hacia México*
}

\author{
Mike Dunning
}

A un cuando el final de la guerra con México pareció marcar el final del movimiento "Todo México", muchos estadunidenses y sureños aún creían que el Destino Manifiesto de Estados Unidos era a la larga dominar el continente. El tiempo gradualmente incorporaría lo que habían dejado otros gobiernos. Según los sureños, 43000 de los aproximadamente 65000 soldados que sirvieron en la guerra con México provenían del Sur. ${ }^{1}$ Algunos escribieron libros basados en sus experiencias. Muchos más mantenían diarios personales. La mayoría escribía a sus casas. En el proceso catalogaron los recursos mexicanos y compararon su explotación con la que creían que podrían lograr algunos estadunidenses. Anotaron las regiones productoras potenciales de algodón, azúcar y tabaco de la época así como las minas legendarias.

Tras la exclusión de la esclavitud en California en 1850, las visiones de estos recursos mexicanos mantenían vivos, en

* Traducción de Sergio A. Fernández Bravo.

1 "The Army in Mexico", DeBow's Review (en adelante $D R$ ), núm. 6 , octubre-noviembre, 1848 , p. 369 .

algunos, los sueños de nuevas zonas de expansión de la esclavitud. La cuestión entonces estaba en si podía lograrse dentro de la Unión. Por lo tanto, los sureños debatían sobre el tiempo que necesitaría la esclavitud para expandirse en esta dirección. Algunos no querían esperar y sus expediciones filibusteras dieron origen a entidades de corta vida como la República de Sierra Madre y la República de Baja California. El anhelo por el éxito de un ferrocarril sureño transcontinental condujo a la "Compra de Gadsden" en 1853.

Aquellos bendecidos por horizontes más amplios vieron que a la larga esta ruta sureña se convertía en central o norteña. En realidad, después de 1850 lo único que restaba del oeste más allá del Mississippi para el Sur era México y algunas otras esperanzas ilusorias.

\section{LA MISIÓN DE LA ESCLAVITUD}

El Compromiso de 1850 que excluía la esclavitud de California y prometía excluirla de Nuevo México parecía poner término a cualquier mayor expansión de la esclavitud en la Unión. La respuesta sureña a esta limitante varió considera- 


\section{SECUENCIA}

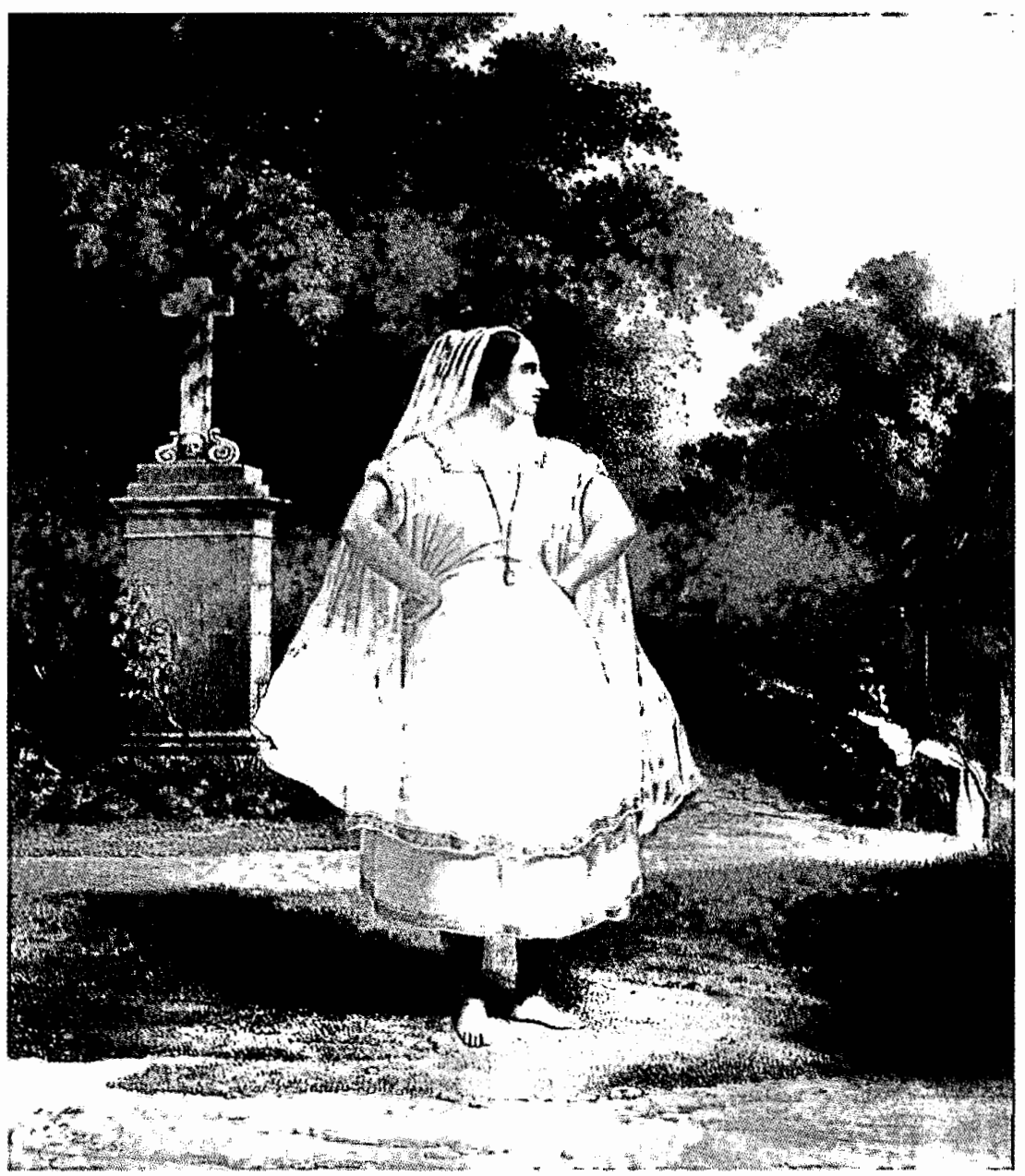

Frédéric Waldeck, Costume des femmes métis à Merida. 
blemente. Lo que más efecto tuvo en la percepción sureña del oeste más allá del Mississipi fueron el desarrollo creciente y la más fuerte reconvención contra las leyes naturales de la esclavitud. Los sureños unían estas leyes a las del Destino Manifiesto y dieron sentido a la misión de la esclavitud en el nuevo mundo. Los espíritus sureños más osados desafiaban al Norte a que interfiriera en la consumación de estas leyes naturales y amenazaron con la desunión. Como resultado de estas tendencias, los avalúos sureños del potencial agrícola de México se volvieron cada vez más positivos. Tras la pérdida de California, también se concentraron cada vez más en la riqueza minera mexicana. La mayoría de los sureños confiaban esta consumación al vago paso del tiempo. Otros no deseaban esperar. Percibían que la inestabilidad mexicana y las fluctuantes condiciones fronterizas seguían ofreciendo la oportunidad de expansión antes de que surgiera su necesidad y estaban deseosos de aprovecharla. Las fortunas mercuriales de la República de la Sierra Madre tentaban a algunos. Los filibusteros Joseph C. Morehead y William Walker atraían a otros. El acuerdo inconcluso de fronteras del Tratado de Guadalupe Hidalgo ofrecía otra esperanza. Cada vez más los sureños percibían que los eventos que surgían del desacuerdo regional con el Norte ligaban su destino con el de México.

El posible fin de la expansión esclavista obligó a los sureños a buscar otras opciones. Un escritor de la DeBow's Review, examinando la "Excesiva población de esclavos -El remedio", hizo notar que

ha sido una idea favorecida entre algunos de nuestros estadistas el adquirir territorio en donde nuestras instituciones esclavistas puedan existir, y por consiguiente preservarnos de una población de esclavos redundante. Cualquiera que haya sido alguna vez la esperanza de que este fuera un esquema factible, creemos que ha sido disipada por los acontecimientos de los últimos cuatro años. Debemos considerar las cosas como son en realidad, y no dejarnos engañar por falsas esperanzas que nunca se realizarán.

Y recomendaba que el Sur convirtiera el trabajo de sus esclavos en algo que compitiera con el trabajo libre blanco del Norte en lo que respecta a manufactura. Otros sugerían además la diversificación de cultivos y una agricultura más intensiva para cortar una mayor dependencia del Norte. Jefferson Davis escribió al pueblo de Mississippi que sin importar lo que el Sur pensara al respecto, existía obviamente el poder en el Congreso para excluir la esclavitud de cualquier territorio que eligiera, en especial desde que el Sur estaba tan obviamente dividido en sus intenciones respecto a esos territorios. En tanto que Davis había intentado sin éxito conseguir más territorio mexicano, otros sureños continuaban lamentando la guerra y el territorio adicionado, ya que era inservible. "H." en DeBow's Review citó a Doniphan diciendo que no cambiaría un buen rancho en Missouri por todo el territorio que había atravesado de Santa Fe a El Paso, Chihuahua, Saltillo, Camargo y Matamoros. Consideraba que el único objeto que el Sur pudo haber esperado ganar del inútil esfuerzo era el acceso al Pacífico. Mary Jane Storms, entonces Mrs. William L. Cazneau, argumentó que el "verdadero sistema sureño" era esta salida al Pacífico - "El Gran Sistema Sureño de la Unión". Consideraba el clamor de una extensión de la esclavitud 
sólo una quimera política. Otros derivaban seguridad de la creencia de que "con la anexión de Texas, el último acre de la región de cultivo del algodón pasaba a estar bajo el ala del Águila, y amenazaba por siempre convertirse en el destino de los estados del Sur", ya que concedía al Sur un monopolio implícito del algodón, tan esencial para la economía mundial. La extensión de la crisis provocada por las nuevas adquisiciones territoriales llegó a enfriar el ardor de algunos antiguos expansionistas. James D. B. DeBow en un artículo publicado en el Progress of the Republic cuestionaba ahora la bondad de una "expansión indefinida". Más allá de la controversia, la última adquisición había incorporado más territorio que los antiguos estados sureños sumados y había dado a Estados Unidos un imperio "más amplio que el de los romanos en sus más orgullosos días de conquista". Aun que preveía más adelante la anexión de México hasta la Sierra Madre, gustosamente hubiera renunciado a toda anexión para evitar la renovación de la crisis y preservar al elemento anglosajón de la república de la degradación con razas inferiores. Mientras que otro escritor cuestionaba "si alguna vez habría otro acre de tierra añadido al territorio esclavista de este continente", o "si habría necesidad de más", él y la mayoría de los sureños concedían que "es claro que el destino de los estados esclavistas está en las manos de la raza. blanca de esos estados". Un creciente número de sureños, sin embargo, eligió unir su destino al de los negros y los mexicanos. Muchos sintieron que no tenían otra

2 "Excessive Slave Population. -The Remedy", DR, núm. 12, febrero, 1852, pp. 182-183; "Jefferson Davis [Warren C.] to the People of Mississippi, sept. elección. ${ }^{2}$

La esclavitud africana significaba la coexistencia de las razas en donde las había. El Sur no pudo escapar a este hecho. Cuando el Norte actuó para bloguear la expansión de la esclavitud, algunos sureños se pusieron a examinar horrorizados las cifras de crecimiento de población de sus esclavos.

Visiones de Haití y Santo Domingo sustituyeron a las de Texas y a las de la evacuación del exceso de esclavos a las nuevas regiones del suroeste. Las legislaturas involucradas del Sur profundo empezaron a debatir leyes que previnieran una mayor emigración de esclavos. Estos preocupados sureños solicitaron una especie de salida para el exceso de sus esclavos con objeto de prevenir una catástrofe racial. Encontraron tanto su razón de ser como su comodidad en lo que llamaron la ley natural de la esclavitud.

Esta ley natural de la esclavitud, tal como fue determinada por los sureños, era en realidad una ley natural de distribución de razas que asignaba a cada una de éstas una zona climática. La zona natural de los negros africanos era el trópico.

9, 1851" en Rowland, Jefferson, 1923, vol. 2, pp. 89, 92, 94; H., "Campaign of the Rio Grande", $D R$, núm. 8 , febrero, 1850 , p. 188; H., "The Sword and the Olive Branch", $D R$, núm. 7, diciembre, 1849, p. 542; Montgomery [Mary Jane Storms], Lacale, 1852, pp. 181, 97; "Speech on the Progress of the United States on the Slavery Question. Delivered at Odd Fellows Hall [Nashville, Tenn.], for the benefit of the Orphan Asylum, by Ex.-Gov. A. V. Brown, in 1850" en Brown, Speeches, 1854, p. 303; James D. B. DeBow, "Progress of the Republic", DR, núm. 7, diciembre, 1849, pp. 471-472, 480, 482, y "Southern Population - It's Density", $D R$, núm. 13, julio, 1852, p. 18. 
Ya que los africanos eran naturalmente perezosos, sólo podían contribuir a la causa de la civilización bajo la guía de una raza anglosajona superior - de aquí la esclavitud.

Una vez que el africano había sido transferido al nuevo mundo, argumentaba el general A. H. Brisbane, su destino lo impulsaría lentamente hacia la zona tórrida semejante a la que tenía en el viejo mundo siguiendo la dispersión de las razas. El doctor Samuel A. Cartwright subrayó que ninguna otra raza podría ejecutar el trabajo fatigoso requerido bajo ese sol y seguir viviendo. Prevenir el acceso del africano y el esclavo a esta región condenaba a otras razas a la muerte o detenía el desarrollo de las necesidades de los trópicos y de sus abundantes recursos. El doctor Van Evne señaló que esa ley había estado en operación en Estados Unidos durante los últimos seis años. "Este movimiento normal y saludable" de los negros hacia el sur era más potente en los estados limítrofes. Más hacia el sur la Providencia había establecido disposiciones geográficas para dar a los esclavos su futuro destino. A lo largo de todas las regiones ecuatoriales había tierras "adecuadas exactamente para la raza caucásica", desde las cuales se podría controlar a los negros que trabajaban en la fértil tierra caliente de las costas. Impedir esto sería condenar a los negros a una aplastante muerte por la creciente presión de los blancos. Más aún, este "flujo de la raza negra hacia el Sur y el Oeste" tenía "un impulso más fuerte que cualquier hombre o gobierno" y podía ;romper todas las barreras que se le opusieran!, argumentaba James Chesnutt. México, "naturalmente adecuado para el trabajo y la población de esclavos", y los mexicanos, "inferiores en energía e inteligencia a la raza blanca, y en capacidad física y resistencia hacia los negros", tendrían que aceptar que "México, que ya requiere empresas debido a su condición aturdida y desamparada, así como por su clima y su suelo, se convertirá en el gran receptáculo de la inmigración de la esclavitud hacia el sur".

Estos sureños también creían que tenían una prueba concluyente de su ley. Chancellor Harper argumentaba que
no existe actualmente sobre la tierra un pue- blo con un clima tropical, o uno cercano a éste, en donde no haya esclavitud, esto es en un alto grado de civilización... México y las repúblicas sudamericanas, que empie- zan su nueva carrera de independencia, y habiendo pasado por una farsa de abolición de la esclavitud, están degenerando rápida- mente, aun hasta el semibarbarismo.

Jefferson Davis señaló que "los productos de México, antes tan importantes y vastos, habían declinado hasta una comparativa insignificancia desde la abolición de la esclavitud". México había de hecho empobrecido tanto desde la abolición que se había visto obligado a vender territorio a Estados Unidos, ofreciendo una "prueba que no puede refutarse sobre la validez de la esclavitud en un suelo y un clima

${ }^{3}$ Gen. A. H. Brisbane, "Negro Civilization in Freedom", $D R$, núm. 10, marzo, 1851, p. 333; Samuel A. Cartwright, M. D., "How to Save the Republic, and the Position of the South in the Union", $D R$, núm. 11, agosto, 1851, pp. 194-195; Dr. Van Evnem, "Slavery Extension", $D R$, núm. 15, julio, 1853, pp. 9-12, y [James Chesnutt], "The Destinies of the South", Southern Quarterly Review (en adelante $S Q R$ ), núm. 23, enero, 1853, p. 203.

4 "Chancellor Harper's Memoir on Slavery", $D R$, núm. 10, enero, 1851, pp. 47-48, y "Speech of Jef- 
como el suyo". 4

La ley natural de la esclavitud y lo relacionado con ésta encaja muy bien con el Destino Manifiesto. "Si, como se ha afirmado a menudo", hizo notar un artículo en el Southern Quarterly Review,

ello probará que la carrera de la raza estadunidense es abarcar a todo el continente, se debe extender hacia los trópicos por la energía del Sur y por la expansión de sus instituciones. Ninguna presión de la población negra nos amenazará jamás con sus males, si los dueños de esclavos hacen su migración patriarcal hacia los trópicos y la civilización llega a establecerse en las riberas del poderoso Amazonas y del Orinoco, por las mismas instituciones que han arrancado al fértil delta del Mississippi de su primitiva condición natural.

Todo formaba parte del "orden de la naturaleza de Dios". “Quién ha argumentado que el hombre civilizado carece del derecho moral para poseer el campo?", preguntaba Chancellor Harper. $\mathrm{O}$ bien, "¿qué se inclinaba a dejar este amplio y fértil continente, capaz de sostener a miríadas de raza civilizada, a unos cuantos bárbaros vagabundos e ignorantes?" Otro sureño, James Duncan Nourse de Kentucky, al menos cuestionó algunas de estas afirmaciones. "Esta idea sólo se vuelve maligna", escribió,

cuando da una confianza racional en una sabiduría, poder y amor elevados, que resaltan lo bueno de lo malo, se le pervierte en la noción presuntuosa de "Destino Manifiesto", que puede servir como pretexto y dis-

ferson Davis in the Senate, feb. 13 \& feb. 14, 1850 , on Slavery in the Territories" en Rowland, Jefferson, 1923, vol. 1, pp. 289-290. fraz para la rapacidad y la ambición.

Nourse, sin embargo, se vanaglorió de la "expansión hacia el oeste de nuestra raza y nuestro sistema social" y de sus "series de milagrosas victorias" derivadas de la colisión de este movimiento con México. ${ }^{5}$

\section{Texiko-MeXas: el Juego de TeXas}

La fuerza de la población en el movimiento hacia el oeste dio apoyo adicional a los expansionistas sureños, ya que

todas las estadísticas de América del Sur indican la extinción, o al menos la declinación, como los resultados más probables de los despotismos monárquicos y militares que han prevalecido y todavía prevalecen, hasta en las más pequeñas porciones del globo.

Simms utilizaba un artículo sobre Louis Kossuth y el derecho de intervención para explicar otra fuerza favorable que funcionaba para México -el ejemplo de Texas. Según Simms,

los territorios restantes de esa rejública están a la espera de la siguiente aplicación del derecho de intervención. Algunas provincias más, en un periodo no distante, se rebelarán, y el pueblo afirmará su independencia. Pedirán nuestra ayuda, en contra de cualquier intento de la república mexicana para reprimirlos con violencia

y el resultado podría ser otra conquista y

5 "Is Southern Civilization Worth Preserving?", SQR, núm. 19, enero, 1851, p. 225; Chancellor Harper, "Memoir on Slavery ", $D R$, núm. 8, febrero, 1850 , pp. 232-243, y Nourse, Mission, 1848, pp. 5 y 10 . 
otra anexión. Una vez más la raza inferior se doblegaría ante la superior, mientras "la doctrina de una estrecha y rígida interpretación de la Constitución que esperaba el momento en que la república podría probablemente extenderse de océano a océano" cómodamente se asentaba en otro territorio. $^{6}$

A medida que más y más sureños aceptaban las interpretaciones de estas leyes y fuerzas, retaban al Norte a que interfiriera contra ellos. "Cuando Texas se halle lleno de nuestros emigrantes, no puede impedírsele a estos cruzar el río Grande y revolucionar las provincias aledañas", se mofaba Thomas L. Clingman:

Ellas están destinadas a ser ocupadas por nuestra población de esclavos. Ellos llenarán toda la región en torno al Golfo, incluyendo a la península de Yucatán, y quizá la porción norte del continente sudamericano... Sea deseable o no, no hay poder en este continente que pueda impedirlo. México es ya demasiado débil. Este gobierno por él mismo no puede hacerlo... Tan pronto sintamos la necesidad real de territorio adicional, lo ocuparemos con o sin la ayuda de este gobierno. Nuestro derecho a tomarlo no será ni mejor ni peor que aquel por el que hemos hecho retroceder la población india original.

Si el Norte intentara prevenir esto o en otra forma forzara la disolución de la Unión, los resultados serían similares, ex-

6 "Spanish American Republics", DR, núm. 7, agosto, 1849, p. 169; [William Gilmore Simms], "Kossuth and Intervention", $S Q R$, núm. 22, julio, 1852, p. 230; Prof. W. J. Sasnett, "The United States -Her Past and Her Future", DR, junio, 1853, p. 629, y "Address of Ex.-Gov. Aaron V. Brown, to the Law Class of the University of Lebanin, February 15, 1853 " en Brown, Speeches, 1854, p. 352. cepto que el Sur se apropiaría los territorios recientemente adquiridos de California y Nuevo México, postulaba Barnwell Rhett. La separada Unión Sureña se anexaría regiones de México tan pronto las necesitara, pero Rhett advertía también que

si con esos potentes recursos y con tan glorioso destino ante ellos, la gente de los estados del Sur permitían ser "encerrados, secuestrados, confinados" por los estados del Norte, y reducidos a sus abyectas colonias, merecerían, y recibirían, el destino de Haití? $^{?}$

No obstante las menciones de desunión eran todavía un poco prematuras en 1850 , aun y cuando algunos sureños creían que "una separación de la Unión provocaría la conexión inmediata de todo el Sur con México y las Indias Occidentales" y una alianza con Inglaterra. Ia apología del profesor James $\mathrm{H}$. Thornwell sobre la muerte de Calhoun en la Universidad de Carolina del Sur resaltaba este punto. Thornwell argumentaba que el destino continental de Estados Unidos y su misión para el mundo requerían ambos la preservación de la Unión y que la muerte de Calhoun era parte de la intervención de Dios para mantener este papel. El Missouri Republican de St. Louis corrigió igualmente al congresista Samuel Williams Inge de Alabama por sus expresiones de desunión. El separatismo de Inge preveía la anexión de Cuba y de México,

${ }^{7}$ Cligman, "Speech on the Future Policy of the Government. Delivered in Committee of the Whole of the House of Representatives, Feb. 15, 1851" en Clingman, Selections, 1878, pp. 277-278; [William Gilmore Simms], "Popular Discourses and Orations", SQR, núm. 20 , octubre, 1851 , p. 340 , y Milledgeville, Federal Union, 8 de octubre, 1850 . 


\section{SECUENCIG}

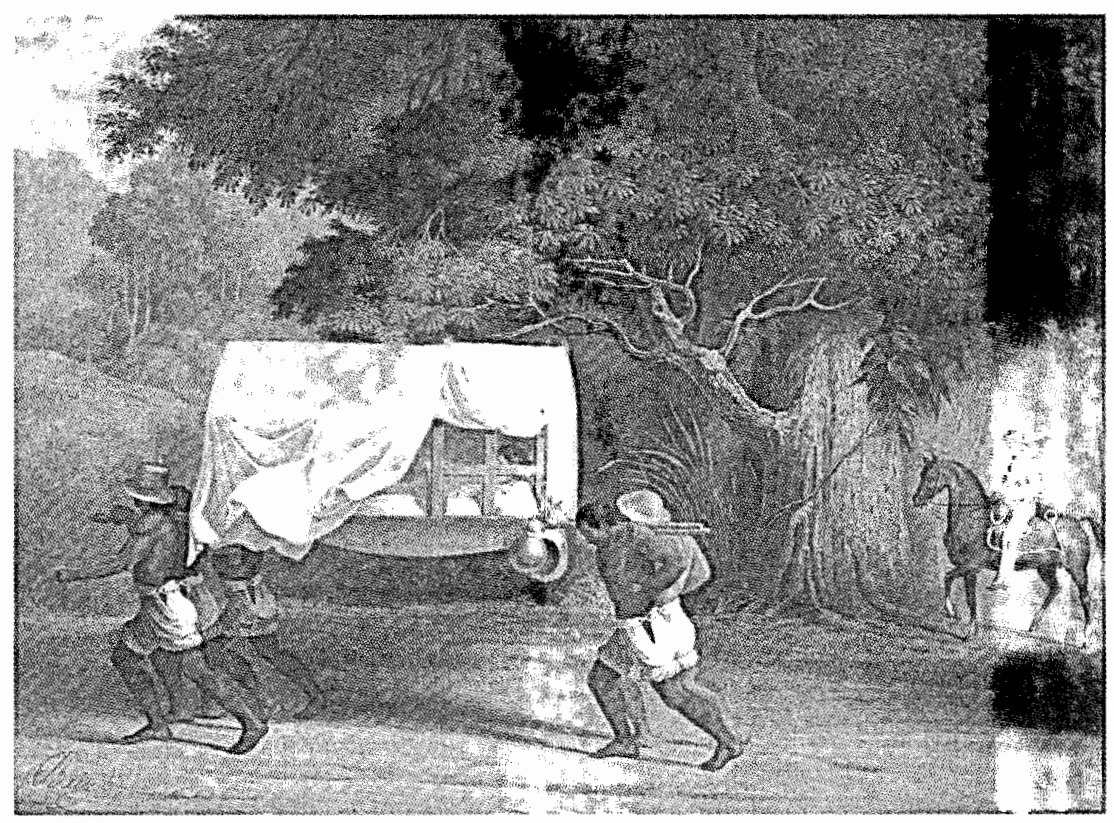

Frédéric Waldeck, Manière de voyager dans Yucatan. 
anunciaba el diario, pero ignoraba a los estados centrales. El valle del Mississippi estaba empezando a cosechar las ganancias de su potencial y no pondría en peligro su éxito permitiendo la separación de la Unión. $^{8}$

Casi todas estas manifestaciones sobre el futuro de la esclavitud revelaron una percepción cambiante sobre México respecto de la más temprana expresada por Calhoun y los whigs del Sur. Este "nuevo" México se aproximaba más estrechamente a la visión del "Todo México" de los del sudeste y a las observaciones de los veteranos sureños, excepto en que, con mayor frecuencia, relacionaba la esclavitud a los recursos mexicanos. México era tomado con un significado más apremiante para los sureños. Cuando DeBow presentó "Excursions to the Heights of Popocatepetl" (Excursiones a la cumbre del Popocatépetl) de Edward Thornton en 1851, lo hizo deseando que

nuestros ciudadanos estuvieran más dispuestos a familiarizarse con el paisaje mexicano con viajes reales de lo que están ahora. Nos complacería por un poco de tiempo revertir los interminables viajes hacia el norte, y pensar que hay bastantes atractivos para hacerlo.

Presentó "Mexico in 1852" del doctor Albert Welles Ely, apuntando que "nues-

8 "Stability of the Union", $D R$, núm. 8, abril, 1850, p. 361; "Thoughts suited to the Present Crisis, a Sermon, on ocassion of the death of the Hon. John C. Calhoun, preached in the Chapel of S. C. College, April 21, 1850, by James H Thornwell, Professor of Sacred Literature and Evidences of Christianity, published by the Students, Columbia, S. C. Printed by A. S. Johnson", Courier, Charleston, 1 de junio, 1850, y "Disunion", Daily Missouri Republican, St. Louis, 26 de febrero, 1850. tro interés en México naturalmente aumenta, y continuará aumentando". "Brantz Mayer's Mexico" de James Morrison Harris, recomendaba hacerlo porque "las ocurrencias de los últimos años han atraído fuertemente la atención de nuestra gente" y porque los sureños estaban "con probabilidad más profundamente involucrados con el futuro de México". Harris creía también que "quien interviene en el tema no puede escapar con facilidad a la convicción de que la absorción, por nosotros, de todo este continente del Norte, es un acontecimiento con toda la probabilidad de ocurrir". A fines de 1853 otro escritor comentó que

hubiera sido una bendición para México si hubiese perdido todo su territorio, cuando fue conquistado por nosotros en la pasada guerra. Se hubiera desembarazado de todos sus tiranos, y gozaría ahora de los beneficios de nuestro gobierno y de nuestras leyes.

Micajah Tarver urgía al gobierno estadunidense a dar los pasos para alentar el comercio y el asentamiento en México, para despertar a los mexicanos de su apatía y desarrollar los recursos largamente descuidados de una de las naciones más ricas del globo. Porque, según concluía Harris en su redacción, "en México no hay ni puede nunca haber lo que se llama espíritu nacional, porque la suya no es una nación", y no podrá existir alguna hasta la emigración de razas superiores. "Las porciones de la Naturaleza más bellas y más selectas en la Tierra", escribió Ely, "están a menudo maldecidas por sus hábi-

\footnotetext{
"Edward Thornton, "An Excursion to the Heights of Popocatepetl”, DR, núm. 10, enero, 1851 , p. 97; Dr. Albert Welles Ely, "Mexico in 1852 ", DR, núm. 13, octubre, 1852, p. 325; [James
} 
tantes"?

Después de 1850 muchos sureños ciertamente consideraban a México uno de los lugares más bellos y únicos, "el jardín mismo de las Hespérides". En vez de dudas de esterilidad aparecieron encomios de insuperable fertilidad. Cuando Cartwright menospreció las regiones azucareras de Cuba y México, otro respondió que su aptitud era tal que cuando esas áreas fueran anexadas y se aplicaran las técnicas utilizadas en Luisiana, el azúcar se terminaría en Luisiana. W. D. Porter argumentaba que el azúcar mexicano era mejor que el cubano; su tabaco era también superior al cubano y producía dos cosechas al año con menos gastos que en cualquier parte de Estados Unidos; y su algodón era abundante y de la más alta calidad. México producía también chiles que el coronel Mausel White había encontrado muy beneficiosos para la preparación de comida para los que laboraban en climas cálidos. Habían por completo evitado el cólera entre el enorme grupo de negros en su plantación de Luisiana

Morrison Harris], "Brantz Mayer's Mexico", SQR, núm. 22, julio, 1852, pp. 118-119; "Commerce and Finances", $D R$, núm. 15, agosto, 1853, p. 198; Micajah Tarver, "The Gulf of Mexico and its Commerce", Western Journal \& Civilian (en adelante WJC), núm. 7, enero, 1952, pp. 224-225; [James Morrison Harris], "Brantz Mayer's Mexico", $S Q R$, núm. 22, julio, 1852, pp. 139-140, y doctor Albert Welles Ely, "Mexico in 1852", DR, núm. 13, octubre, 1852, p. 325 .

10 "Editorial and Literary Department", $D R$, núm. 11, septiembre, 1852 , p. 356; "Remarks on Dr. Cartwright's Paper -'Extension of the Sugar Region'”, $D R$, núm. 15, diciembre, 1853, pp. 647648 ; W. D. Porter, "Products of Mexico-Sugar, Cotton, Rice, Indigo, etc.", $D R$, núm. 11, octubre, 1851, pp. 413-415, y "Pepper", $D R$, núm. 11, noviembre, durante las recientes epidemias. ${ }^{10}$

Los sureños prontamente calmaron sus dudas respecto a la producción mexicana de algodón con igual facilidad. Algunos hicieron notar que aunque los españoles habían encontrado a los antiguos mexicanos cultivando algodón, los mexicanos modernos habían perdido ese arte desde ese entonces. William W. Carpenter, que caminó más de 2500 millas por México, había descubierto regiones potenciales para el cultivo de algodón en las áreas de sus viajes, y predijo que aun cuando México cosechaba poco algodón, podía cosechar la cantidad que quisiera. La conclusión parecía obvia, México nunca sería exportador de algodón "hasta que otra gente poseyera sus fértiles valles". 11

Aparte del potencial agrícola y de la oportunidad, los sureños mostraron un interés creciente en los recursos minerales de México, especialmente tras su exclusión de California. La riqueza mineral de México había gozado de notoriedad mundial desde hacía tiempo. El Sur compartía ahora la esperanza de Ely de que

al igual que en California, la extensión exacta de su riqueza mineral no se desarrollará hasta que pase a manos más ilustradas. En el momento en que México caiga en manos de la raza anglosajona, se explorará cada

1851, pp. 508-509. Compárese la elaboración de White respecto a su pimiento tabaco rojo con el origen de la famosa "Tabasco Brand Pepper Sauce" de McIlhenny Co., en Art, s. a., pp. 1-2.

"DeBow, "Early and Growing Commerce of the United States", $D R$, núm. 9, octubre, 1850, p. 388; Carpenter, Travels, 1851 , p. 278; "Editorial and Literary Department", $D R$, núm. 11, noviembre, 1851, pp- 546-547; $S Q R$, núm. 21, enero, 1852, pp. 232-233, y R. H. G., "The Southern States", $D R$, núm. 8, enero, 1850 , p. 55. 
pie de su territorio, y con toda probabilidad, serán traídas a la luz maravillas minerales que igualarán, si no eclipsarán, las de California.

Brantz Mayer concluyó su avalúo de "Mexican Mines and Mineral Resources in 1850" (Minas mexicanas y recursos minerales en 1850) para el DeBow's Review haciendo notar los cambios que la explotación estadunidense había aportado al desarrollo de California. Carpenter, que probablemente había visto y visitado tantos emplazamientos mineros como cualquier otro sureño, a excepción de Gregg, y había trabajado en varios, hizo notar de qué manera los extranjeros controlaban ya muchos de los mejores. Hizo también una analogía con California, "Lo que es México ahora, lo era California"; escribió: "lo que ahora es, México podría serlo, si estuviese bajo un gobierno similar. Tiene todas las ventajas de California, con pocas de sus desventajas". $Y$, según observaba Ely: "sería una bendición para México si alguna nación ilustrada lo conquistara -una fácil tarea hasta ahora... Nuestros vecinos mexicanos son un escándalo, y merecen un castigo atroz." 12

Aun cuando México gozó de cinco años de calma relativa después de la guerra, los sureños prefirieron apuntar a los desacuerdos que todavía existían. José Joaquín Herrera había subido a la presidencia en junio de 1848. Mariano Arista lo sucedió pacíficamente en 1851 y gobernó hasta 1853, cuando se rebelaron los conservadores y restauraron a Santa Anna en

${ }^{12}$ Doctor Albert Welles Ely, "Mexico in 1852", $D R$, núm. 13, octubre, 1852, pp. 336-337; Brantz Mayer, "Mexican Mines and Mineral Resources in 1850 ", $D R$, núm. 9, julio, 1850 , pp. 40-41; Car- el poder. Durante este periodo, la prensa sureña reportó el desorden y caos continuo. Vieron a Paredes armando problemas, y observaron a Santa Anna en el exilio y el comportamiento de los santannistas en México. Debido a la presencia de voluntarios estadunidenses, estuvieron al tanto de la guerra india que ocurría en Yucatán y de sus desastres y su falta de progreso. El interés en las minas mexicanas atrajo su atención a la guerra civil en Sonora. Inicialmente, sin embargo, la prensa prestó mayor atención a la revivida República de la Sierra Madre. El Courier de Charleston señaló en 1849 que los separatistas dirigidos por Vital Fernández habían persistido en el acoso de Tamaulipas. El Picayune reportó que la banda conocida como "Ousel Owls" estaba todavía activa y podía aún arrancar algunas plumas al águila mexicana. Poco después la República lanzó de nuevo una declaración de independencia. El documento atribuía el plan a Arista y al doctor Millet, aunque Arista rápidamente arrestó a Millet para desbaratar este "intento de locos". Hacia 1850 nuevamente la revuelta pareció terminarse. No obstante, José Carvajal izó de nuevo la bandera en 1851. Los editores del Weekly Appeal de Memphis suplicaron al igual que el Sur no permanecer insensibles al "destino manifiesto" de estos acontecimientos, puesto que Cuba y México eran las únicas áreas en donde el Sur podía tener esperanza de resucitar su poderío. Describieron las tierras de la República ricas y hermosas y por completo adecuadas a los grandes em-

penter, Travels, 1851, pp. 80, 140-141, 211, 227 , 240-242, 257, 270-271, 284-286, 288, y doctor Albert Welles Ely, "Mexico in 1852", DR, núm. 13, octubre, 1852, p. 354. 
porios sureños de azúcar y algodón. Continuaron estos informes iniciales con testimonios más amplios sobre el potencial de la región como exportadora de algodón y tabaco. Mary Cazneau hacía resonar alabanzas desde el pueblo fronterizo de Eagle Pass. Urgía al Sur a explotar esta oportunidad dorada para asegurar su salida hacia el Pacífico, ya que la nueva república podría conceder derechos liberales de vía a cambio de reconocimiento. Consideraba que todo lo que necesitaba el movimiento era un líder que asegurara su éxito. Como resultado, la gente rogó por el derrocamiento de Arista en la ciudad de México, para que pudiera volver a dirigir la empresa desde hacía tiempo asociada con su nombre. Sin embargo, antes de que eso sucediera, el ejército mexicano derrotó a Carvajal y forzó a sus filibusteros a huir al lado estadunidense del río. El cirujano Samuel P. Moore, apostado con el ejército estadunidense en Fort Brown, escribió al director del Arkansas Gazette diciendo que Carvajal merecía "conocer el interior de una penitenciaría" y que el país era sólo "adecuado para greasers, ${ }^{13}$ que no quieren otra cosa que maíz para torti-

\footnotetext{
${ }^{13}$ Literalmente, engrasadores. Término despectivo para designar a los mexicanos [N. del T.].

${ }^{14}$ Faulk, North, 1967, p. 123; "Important from Mexico", Reteille, St. Louis, 8 de mayo, 1849; "Late from Vera Cruz", Register E Joumal, Mobile, 22 de diciembre, 1849; "From Carthagenia", Courier, Charleston, 18 de julio, 1850; "Santa Ana", Reveille, St. Louis, 18 de octubre, 1849; "From Tampico", Picayune, Nueva Orleans, 20 de octubre, 1849; Soutbern Advocate, Huntsville, 7 de enero, 1852; "Ravages in Yucatan", Reveille, St. Louis, 3 de febrero, 1849; Picayune, Nueva Orleans, 6 de febrero, 1849; "From Yucatan", Picayune, Nueva Orleans, 26 de junio, 1849; "From Yucatan-Defeat and Slaughter of Go-
}

llas y tabaco para cigarritos". ${ }^{\text {i4 }}$

El tercer eclipse de la República de la Sierra Madre dirigió la atención del Sur hacia la oportunidad de Sonora. Al igual que el resto del norte de México, Sonora había sufrido muy dolorosamente los devastadores ataques de apaches y comanches. Algunos sureños estaban preocupados porque Estados Unidos hubiese comprado estos indios "por una valiosa gratificación" y se convirtiera en heredero del problema "por el más incuestionable de los títulos". Otros, como Jefferson Davis, preferían hacer notar que Estados Unidos había comprado entre los pueblos, los pima y otras tribus sedentarias, "una clase de indios industriosos e inclinados a depender de la raza blanca, más que, como los hijos de Esaú, a meterse a la selva y vivir de su caza". En cualquier caso, Estados Unidos demostró ser incapaz de cumplir su obligación por tratar de prevenir ataques indios en sus incursiones acos-

vernment Troops", Courier, Charleston, 9 de julio, 1849; "Later from Yucatan", Reveille, St. Louis, 18 de octubre, 1849; "Later from Havana", Courier, Charleston, 3 de noviembre, 1849; "Yucatan", Courier, Charleston, 12 de enero, 1850; "Mexican Items", Courier, Charleston, 30 de abril, 1849; "Republic of Sierra Madre-The Owls are on the Wing", Picayune, Nueva Orleans, 26 de junio, 1849; "Republic of Sierra Madre", Picayune, Nueva Orleans, 26 de junio, 1849; "Republic of Sierra Madre", Reveille, St. Louis, 10 de noviembre, 1849; "From Brazos", Picayune, Nueva Orleans, 9 de marzo, 1850; Weekly Appeal, Memphis, 8 de octubre, 1851; "The Valley of Sierra Madre", Weekly Appeal, Memphis, 19 de noviembre, 1851; Montgomery [Cazneau], Eagle, 1852, pp. 179, 182, 186, 188; Weekly Appeal, Memphis, 7 de enero, 1852; Southern Advocate, Huntsville, 17 de marzo, 1.852, y "Samuel Preston Moore [Fort Brown] a William E. Woodruff, 28 de julio, 1853" en Payne, "Samuel", 1956, p. 237. 
tumbradas a través de la nueva frontera, y dejó a la fila norte de los estados mexicanos a merced de los indios. ${ }^{15}$

La respuesta mexicana a estos problemas siguió varios esquemas que parecieron ofrecer otra oportunidad para la expansión sureña. Algunos de los estados contrataron de nuevo guerrillas estadunidenses o cazadores de cueros cabelludos. Los mexicanos no estaban tan preocupados como los nuevos administradores del territorio de Nuevo México, quienes ponían en ejecución un programa de exterminio contra los enemigos. En segundo término, intentaban hacer que el gobierno central aprobara esquemas para establecer colonias civiles y militares a lo largo de la frontera. En el verano de 1849, el coronel José María Carrasco de Sonora pidió incluso la intervención estadunidense. Algunos sospechaban de la intromisión de Paredes en este asunto, mientras que otros abogaban esperanzados por la anexión a Estados Unidos. Todas estas acciones sirvieron para acrecentar el interés sureño en las minas de Sonora. El Picayune reportó que la población estaba huyendo de Sonora por California a causa de los indios, no por el oro, ya que el oro de Sonora era más rico que el de Sacramento. Apuntó que Sonora tenía reputación de ser el placer de oro más rico del mundo y

1.5 "Mexican items", Courier, Charleston, 30 de abril, 1849; Southern Advocate, Huntsville, 2 de abril de 1851; "From the Rio Grande", Picayune, Nueva Orleans, 22 de enero, 1850; "Population of the United States", Southern Recorder, Milledgeville, 25 de febrero, 1851; "Remarks of Jefferson Davis on bill to establish the Department of the Interior, March 3, 1849" en Rowland, Jefferson, 1923, vol. 1, p. 234; Hoopes, Indian, 1932, pp. 23-25, 166-169, y Faulk, North, 1967, pp. 78-80. que compañías británicas, escocesas y estadunidenses se estaban organizando para ir ahí, luchar con los apaches y obtener el oro. Más aún, reportó que el gobierno mexicano estaba intentando alentar la emigración, concediendo términos más liberales que los de Texas y que muchos estadunidenses estaban ya en camino. Thomas Jefferson Green, quien se encontraba en Nueva Orleans equipando una expedición con esclavos para California, anunció que en vez de ello podría ir a Sonora. ${ }^{\mathrm{l} .6}$

No hay que decir que las visiones de otra Texas aparecieron en las mentes del Sur. Aun cuando algunos sureños, como William R. Burwell de Virginia, argumentaron que no volvería a haber otro "drama texano" a pesar de las minas de Sonora, Chihuahua y Durango, muchos otros sureños no estaban tan seguros. No tenían ni los pesares de Burwell ni sus intereses privados en otro proyecto. Mejor se unieron a la humorística y gloriosa milicia del Picayune que anunció:

Who's afraid? What's Mexiko, Californiko, and Oregon? Who's afeered of them? Sodyers! The mortal $9999^{\text {th }}$ can trash the life out of that ar' yaller, half Spanish warmit, that Mexiko, any mornin' afore breakfast. Our motto is, "Liberty and Death, now and forever, one and inseparable!" Whooray for Mexas!

16 "From Tampico", Picayune, Nueva Orleans, 20 de octubre, 1849; "Great Fight With the Apaches", Picayume, Nueva Orleans, 20 de octubre, 1849; Faulk, North, 1967, pp. 109, 117; Stout Jr., Liberators, 1.973, pp. 27-38, y "Mexico: Route to California -Gold Placers of Sonora", Picaymne, Nueva Orleans, 26 de junio, 1849.

${ }_{17}$ William R. Burwell, "Tehuantepec and Its Title", $D R$, núm. 14, enero, 1853, pp. 17-18, y "The Glorious Militia!", Federal Union, Milledgeville, 23 


\section{SECUENCIA}

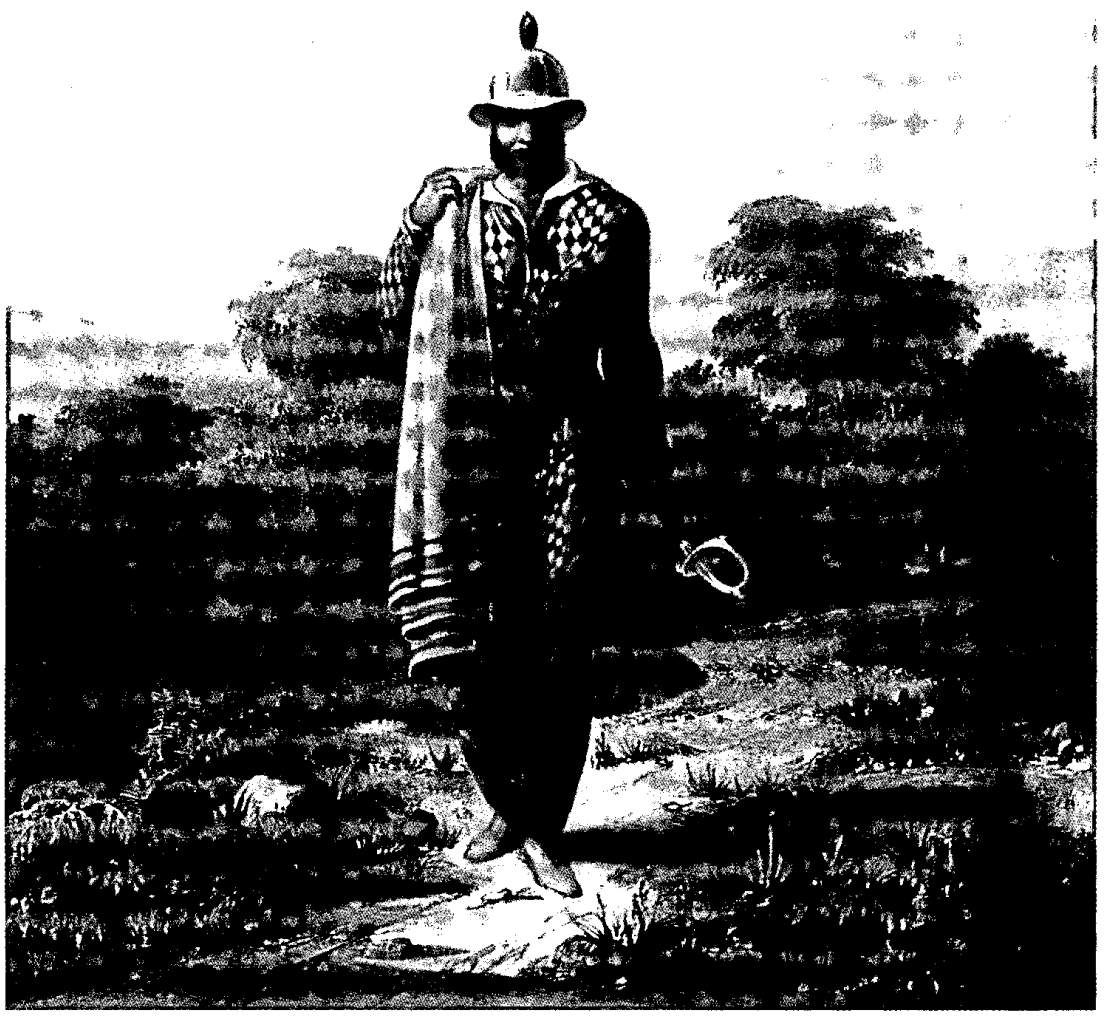

Frédéric Waldeck, Costume de majordome des fermes. 
Down eith Texiko! Let's lick her! ${ }^{17}$

Además de estas consideraciones sureñas sobre México, el descubrimiento de oro en California había atraído a miles de estadunidenses al Pacífico. Tras el dinero fácil de los primeros años, California retenía muchos mineros descontentos y ociosos. Gregg consideraba que la "fiebre del oro" de California podía acelerar grandemente el Destino Manifiesto una vez que los "miles y decenas de miles de espíritus aventureros que se han congregado ahí... empiecen a buscar otra cosa qué hacer". Escribiendo en Mazatlán, consideraba que

de esta manera... toda la costa del Pacífico sería ocupada tan al sur como este lugar, y finalmente más allá. Así, con los aventureros de California por un lado, y el invasor espíritu de Texas por el otro, no veo posibilidad para la existencia del actual gobierno mexicano.

\section{Clingman anunció en la Cámara que}

no se sorprendería, en ningún momento, de escuchar que los aventureros buscadores de oro ahora en California, hubieran organizado una expedición y capturado las provincias mexicanas inmediatas al sur.

No tuvo que esperar mucho para saber

de octubre de 1849. Una versión muy aptoximada del texto en inglés macarrónico, sería así: "¿Quién tiene miedo? ¿Qué cosa es Mexiko, Californiko y Oregón? ¿Quién les teme? ¡Soldados! El mortal 9999 puede podarle la vida a ese vociferante gusano medio español, ese Mexiko, cualquier mañana, antes de desayunar. Nuestro lema es " $\mathrm{i}$ Libertad y Muerte, ahora y siempre, una e inseparable! ¡Hurra por Mexas! ¿Abajo el Texiko! ¡Azotémosle! [N. del T.].

${ }^{18}$ Gregg, "Diary" en Fulton, Diary, 1941, vol. 2, pp. 324-325, y Clingman, "Speech", 1878, p. 277. del primer intento. ${ }^{18}$

A finales de 1850 Joseph C. Morehead, oficial general de intendencia de California, salió hacia el sur con una expedición para someter a los yuma por el asesinato de la banda de antiguos cazadores de cabelleras de John Joel Glanton. El ejército permaneció en el lugar y reclutó caminantes de Arkansas y Texas en su camino a los campos de oro. Morehead continuó reclutando a principios de 1851 y lanzó un ataque por mar y tierra sobre Baja California y Sonora. Los mexicanos dispersaron con facilidad a esos autoproclamados luchadores contra indios, colonizadores y mineros desempleados. ${ }^{19}$

Mientras tanto continuaron circulando informes en el Sur y en California diciendo que había agentes mexicanos ofreciendo en venta Baja California, Sonora y Chihuahua, para aliviar la deuda que agobiaba al gobierno mexicano. El Weekly Appeal de Memphis promovió este aumento potencial del poder de la esclavitud. Más adelante reportó que México o bien se vendía a sí mismo a Europa o seguía el ejemplo de Texas y buscaba anexarse a Estados Unidos. Persistían también los reportes de movimientos en Sonora favorables a la anexión estadunidense, como los de hostilidad hacia "Los americanos" que viajaban por México, que el Southern Recorder de Milledgeville consideraba que podrían dar a "los 'filibusteros' de California el pretexto que necesitaban para atacar". Encima de esto, los diarios de California reportaron exportaciones de oro en Guaymas con valor de 5000000 de dólares en 1848, y 2500000 en 1851 . Algunas expediciones de irritados mine-

${ }^{19}$ Stout, Liberators, 1973, pp. 38-46, y Weekly Appeal, Memphis, 25 de junio y 16 de julio, 1851 . 
ros franceses de California buscaban sin éxito explorar esta oportunidad. Sin embargo, el éxito del conde Gaston Raousset-Boulbon en 1852 presentaba esperanzas a muchos otros grupos interesados. ${ }^{20}$

Uno de estos grupos se reunió en $\mathrm{Pla}$ cerville en 1852, bajo la dirección de William Walker de Tennessee y su compañero de leyes Henry P. Walkins, un sobrino de Henry Clay. En la primavera de ese año enviaron a Frederic Emory a Guaymas, Sonora, con el fin de asegurarse concesiones de tierra para la colonia emigrante del grupo. El gobierno de Sonora tenía las manos llenas con Raousset-Boulbon y desairó a Emory. Hacia mayo de 1853 , no obstante, el grupo ya se encontraba vendiendo bonos para la República de Sonora en California. Posteriormente, en junio, tras el fracaso de Raousset-Boulbon, Walker y Watkins fueron a Guaymas a probar la reacción ante los "colonizadores" estadunidenses. Evitaron al gobernador Manuel María Gándara, pero encontraron la raison d'être de su "colonia" -la necesidad de protección de Sonora contra los apaches. Tras su regreso a California, Walker reunió su ejército y partió de San Francisco en el Caroline. El 3 de noviembre de 1853 desembarcó en La Paz, Baja California, y proclamó la República de Baja California. El presidente Walker estableció entonces el comercio libre y promulgó el Código Civil de Luisiana [un estado esclavista] como la ley de su tierra. Pronto se mudó al norte, a Ensenada, en donde se dirigió al pueblo de Estados Unidos. "Cuando los habitantes de un

${ }^{20}$ Weekly Appeal, Memphis, 18 de julio y 13 de agosto de 1851; Southern Recorder, Milledgeville, 8 de julio, 1851; Stout, Liberators, 1973, pp. 49-78, y Weekly Appeal, Memphis, 12 de enero de 1853. territorio fracasan casi enteramente en desarrollar los recursos que la naturaleza ha puesto entre sus manos", anunció el presidente,

los intereses de la civilización requieren que otros vayan y posean la tierra. No puede ni debe permitírseles ser los guardianes del rebaño, e impedir que otros posean lo que ellos no han podido ocupar y poseer.

El presidente dijo a la gente de Baja California: "sobre cualquier cosa deseamos establecer el orden y la paz, en donde antes todo ha sido anarquía y confusión". Poco después cambió el nombre a República de Sonora, y a continuación se anexó el estado mexicano. Luego se dirigió a su ejército, exclamando:

¡Vosotros, soldados! estáis ahora llamados a arrebatar el país del dominio de los apaches, y hacerlo la morada del orden y la civilización... Cuando ataquéis a un enemigo mexicano, recordad que atacáis a un ayudante de los apaches -a un ayudante en el asesinato de niños inocentes, y en la violación de mujeres desamparadas. Llenad vuestras mentes con estas ideas y la victoria llegará a las llanuras de Sonora.

Todas estas grandiosas declaraciones emanaban de la base de Walker cerca de Ensenada y de la parte superior de Baja California, en donde el bandido Guadalupe Meléndez mantuvo a raya a los efectivos de Walker hasta que finalmente los obligó a huir por la frontera a Estados Unidos. Había pasado otra oportunidad. Primero Yucatán, luego las varias repúblicas de la Sierra Madre, y ahora se unía a

${ }^{21}$ Stout, Liberators, 1973, pp. 81-100, y Woodward, Republic, 1966, pp. 13, 18, 27, 32, 34, 43-44, 57-58. 
ellas la República de Sonora. ${ }^{21}$

Mientras que Walker llevaba a cabo sus hazañas en el noroeste de México, la nueva administración de Franklin Pierce exploraba una nueva oportunidad para adquirir más territorio mexicano. La oportunidad surgió del fracaso para finalizar la nueva frontera entre México-Estados Unidos de acuerdo con el Tratado de Guadalupe Hidalgo. Polk, en el ocaso de su administración, había nombrado a John B. Weller comisionado estadunidense de límites. Una vez en el lugar Weller encaró los problemas de la fiebre de oro, con inflación de los alimentos y abastos, deserciones, ayuda a buscadores de oro exhaustos y menesterosos en los caminos del sur, y la interferencia política de Washington luego del cambio de administración. Taylor destituyó sin ninguna ceremonia a Weller con cargos de malversación y corrupción y lo reemplazó con el bibliófilo de Rhode Island, John R. Bartlett. Poco después de que Bartlett recibiera el cargo, aceptó la interpretación mexicana del incorrecto mapa de Disturnell utilizado en las negociaciones del tratado, el cual colocaba la línea mucho más al norte de la señalada por su topógrafo A. B. Gray. Éste protestó con vehemencia que la línea del norte Bartlett-Conde dejaba fuera al fértil valle de La Mesilla y la ruta para un ferrocarril transcontinental, por lo cual renunció. Mientras tanto, California había colocado a Weller en el Senado de Estados Unidos, desde donde lanzó una investigación de la Comisión de Límites que terminó en el Comité de Relaciones Exteriores del virginiano James W. Mason. Tras testimonios de Gray y de los otros descontentos miembros del grupo de agrimensores, el comité de Mason repudió la línea Bartlett-Conde y censuró la labor de Bartlett. Los tejanos Volney E. Howard en la Cámara y Rusk en el Senado condujeron la disputa respecto a la línea, la que el Congreso rechazó en el verano de 1852. Esto dejó el límite exacto en disputa, aunque el nuevo gobernador de Nuevo México, William Carr Lane, rápidamente confiscó el territorio en cuestión. ${ }^{22}$

Cuando Pierce tomó el asunto resolvió señalar la frontera y adquirir acaso más territorio. El nuevo secretario de Guerra, Jefferson Davis, consiguió el nombramiento como ministro en México para el ferrocarrilero de Carolina del Sur, James Gadsden. Éste consultó con Gray respecto a la frontera y salió hacia México para iniciar negociaciones con el nuevo gobierno de Santa Anna. Gadsden encontró al nuevo gobierno muy inestable, encarando la posibilidad de una nueva revolución, y con mucha necesidad de dinero. Santa Anna estaba deseoso de hablar, pero la situación demandaba darse prisa. La administración de Pierce envió entonces cinco opciones de negociación a Gadsden. La primera ofrecía 50000000 de pesos por los estados norteños de Coahuila, Chihuahua, Sonora y todo Baja California; la segunda movía la línea más al norte y excluía a Baja California por 35000000 de pesos; la tercera continuaba el retiro hacia el norte pero incluía a Baja California por 30000000 de pesos; la cuarta ofrecía la misma línea sin Baja California por 20000000 de pesos; y la quinta pedía sólo tierra para el ferrocarril transcontinental. En este punto de las negociaciones secretas, Walker atacó La Paz y reanimó el fuego de la xenofobia mexicana.

${ }^{22}$ Goetzmann, Exploration, 1972, pp. 261-263, y Faulk, North, 1967, pp. 75-76, 105-106, 118. 
Santa Anna necesitaba desesperadamente dinero y quizá vio la inevitable intención de Walker, pero sólo accedió a la última oferta de Gadsden. Tras algunas modificaciones del Senado, el Congreso aceptó la compra de Gadsden. El Sur había perdido otra oportunidad para adquirir cuantioso territorio mexicano. ${ }^{23}$

Los años de 1846 a 1853 habían sido extraordinarios en las relaciones entre Estados Unidos y México, y afectaron profundamente la percepción del futuro por el Sur. La guerra con México y sus objetivos habían mantenido la hendidura partidista entre whigs y demócratas sureños $\mathrm{e}$ intensificó las diferencias regionales entre los demócratas del sureste y los del suroeste. Tras la amenaza de la cláusula Wilmot de excluir la esclavitud de todo territorio adquirido a México, Calhoun y otros intentaron unir al Sur en un programa de derechos sureños y alentar la división de sus peligros. Aun bajo esa amenaza, el Sur se dividió en campos opuestos de whigs "no territorio" y sureños del oeste, seguidores de "Todo México". El resultado final de la guerra que siguió a la conquista de México por Scott dejó a ambos grupos insatisfechos. Habían obtenido la paz, pero también habían renovado la crisis sobre la esclavitud. El Sur ya no tenía asegurado el lejano oeste del Compromiso de Missouri, ni tampoco un espacio para la extensión de la esclavitud hacia el oeste.

Sin embargo, aquellos sureños que deseaban "Todo México" no desesperaron totalmente. En vez de ello volvieron su

${ }^{23}$ Faulk, North, 1967, pp. 123, 128-138; Stout, Liberators, 1973, p. 138, y Persifor F. Smith [San Antonio] a Davis, 22 de diciembre, 1853, en Rowland, Jefferson, 1923, vol. 2, pp. 338-339. atención hacia México en donde el caos y la inestabilidad parecían ofrecer oportunidades de mayor expansión. Los veteranos de la guerra mexicana habían catalogado los recursos que esperaban explotación. La creencia en la ley natural de la esclavitud con su migración hacia el sur y en un destino manifiesto hacían parecer inevitable ese futuro. En tanto que las oportunidades pasajeras como las de Yucatán, la República de Sierra Madre, la República de Sonora y la compra de Gadsden eludían a estos sureños, ellos mantenían su visión de la inevitable marcha de la esclavitud hacia los trópicos. Su realización podría estar encerrada en el seno del tiempo, pero estaban seguros de que se encontraba ahí. Mientras tanto buscarían aprovechar cada oportunidad que se presentara para acelerar el proceso.

\section{Hemerografía}

Courier, Charleston, 1850.

Daily Missouri Republican, St. Louis, 1850).

Federal Union, Milledgeville, 1849.

Picayune, Nueva Orleans, 1849.

Register E Journal, Mobile, 1849.

Reveille, St. Louis, 1849.

Southern Advocate, Huntsville, 1852.

Soutbern Recorder, Milledgeville, 1851.

Weekly Appeal, Memphis, 1851.

\section{BiBLIOGRAFÍA}

-Brown, Aaron V., Speeches, Congressional and Political, and Other Writings of Ex Governor A aron V. Brown of Tennessee, John L. Marling and Company, Nashville, 1854.

-Carpenter, William W., Travels and Adventures in Mexico, Harper \& Brothers, Nueva York, 
1851.

-Clingman, Thomas L., Selections from the Speeches and Writings of Hon. Thomas L. Clingman, of North Carolina, John Nichols, Book \& Job Printing, 2a. ed., Raleigh, 1878.

the Government, Delivered in Committee of the Whole of the House of Representative, Feb. 15, 1851" en Clingman, Selections, 1878.

-Faulk, Odie B., Too Far North...Too Far South, Westernlore Press, Los Ángeles, 1967.

-Fulton, Maurice Garland (coord.), Diary $\mathcal{E}$ Letters of Josiah Gregg: Southwestern Enterprises, 1840-1847, University of Oklahoma Press, Norman, 1941.

-Goetzmann, William H., Exploration $\varepsilon$ Empire: The Explorer and the Scientist in the Winning of the American West, Vintage Books, Nueva York, 1972.

-Hoopes, Alban W., Indian Affairs And Their Administration, with special reference to the Far West, 1849-1860, University of Pennsylvania Press, Filadelfia, 1932.

-Montgomery, Cora [Mary Jane Storms], The Eagle Pass; or, Life on the Border, George P.
Putnam \& Co., Nueva York, 1852.

-Nourse, James Duncan, The Mission and Problem of American Society, and Address Delivered Before the Literary Societies of Centre College, 28 junio, 1848, Zimmerman \& Barbee, Prs., Danville, $\mathrm{KY}, 1848$.

-Payne, John W. (coord.), "Samuel Preston Moore's Letters to William E. Woodruff', $A r$ kansas Historical Quarterly, núm. 15, agosto, 1956.

-Rowland, Dunbar (coord.), Jefferson Davis, Constitutionalist, Mississippi Department of Archives \& History, Jackson, 1923, vol. 2.

-Stout Joseph Allen Jr., The Liberators: Filibustering Expeditions into Mexico, 1848-1862, Westernlore Press, Los Ángeles, 1973.

-The Art of Seasoning, McIlhenny Co., Avery Island, L. A., s. a.

-Woodward, Arthur (coord.), The Republic of Lower California, 1853-1854: In the Words of Its State Papers, Eyewitnesses, and Contemporary Reporters, Dawson's Book Shop, Los Ángeles, 1966. 